\title{
Genetic Merit Based Genotype Selection for Physical Fruit Traits in Mango
}

\author{
Arun Kumar Barholia ${ }^{1 *}$, SangeetaYadav ${ }^{1}$ \\ ${ }^{1 *}$ Rajmata Vijayaraje Scindia Krishi Vishwa Vidyalaya, R. A. K. College of Agriculture, Sehore 466001 M.P. India
}

\section{A R T I C LE INFO}

\section{Article history:}

Received 28 March 2014

Accepted 20 June 2014

Available online, ISSN: 2148-127X

Keywords:

Genotypes

Mango on year

Selection indices

Discriminate function coefficients

Physical fruits traits

\begin{abstract}
A B S T R A C T
Selection indices based on their genetic merit of fruit characters were constructed for fruit yield/tree in 48 genotypes in mango (Mangifera indica L.). Genotypes, SBM 01-35, SBM 01-26, SBM 01-9, SBM 01- 10 and SBM 01-26 in on year while, SBM 01-12, SBM 01-36, SBM 01-26, SBM 01-28 and SBM 01-9 in off year recorded highest fruit yield /tree. Genotypes SBM 01-10, SBM 01-36, SBM 01-09, SBM 01-30 and SBM 01-6 exhibited comparatively high estimates of selection indices during on year while, SBM 01-36 followed by SBM 01-12, Totapari, SBM 01-17 and SBM 01-29 showed the maximum estimates of selection index for fruit yield/ tree during off year. Alphonso followed by SBM 01-5, SBM 01-13, Langra and SBM 01-14 during on year and Dashehari, Safeda, SBM 01-3 and SBM 01-39 in off year exhibited the minimum estimates of varietal indices. Genotypes differed considerably in their ranking pattern based on selection indices. Genotypes SBM 01-9, SBM 01-10, SBM 01-30, SBM 01-6 and SBM 01-36 showed maximum varietal indices and phenotypic performance in both the years thus, appeared promising for use as parent in mango improvement programme.
\end{abstract}

\section{Introduction}

Mango (Mangifera indica L.) is the king of tropical fruits. The important mango growing countries are India, China, Thailand, Mexico, Pakistan, Philippines, Indonesia, Brazil, Nigeria and Egypt. India is the largest producer in the world. The productivity of this crop is $8.43 \mathrm{~m}$ ton/ha which is low and needs improvement. The selection of genotypes based on phenotypic performance or yield per se is not much effective due to presence of genotype-environment interaction in phenotypic expression of the genes. On the other hand, selection based on genetic merits of several characters in the form of selection indices using discriminant function analysis of Fisher (1936) has been found a powerful tool in selection breeding programme. This analysis discriminate the economic genotypes from a population based on their genetic merits. However, the practical utility of this technique has not been tested in mango. In the present study, an attempt was therefore, made to select out the promising genotypes for fruit yield/tree based on genetic merits of fruit characters in mango (Mangifera indica L.).

\section{Materials and Methods}

The material of the present study comprised forty eight genotypes comprising 31 landraces from Bhopal division of Madhya Pradesh, 15 improved varieties and
02 hybrids, which were selected based on popular fruit characters like fruit size, suitability for pickles, sucking and table purposes, peel colour, firmness of pulp, flavor and storability. These genotypes were evaluated for physical characters of fruit in randomized complete block design with three replications in two subsequent on and off years. Two trees per genotype were randomly selected in each replication after fruit set. The fruits of selected trees were collected from each genotypes in each replications at full maturity stage and subjected to ripening for recording observations on fruits/ tree, fruit yield/tree $(\mathrm{kg})$, weight per fruit $(\mathrm{g})$, length and width of fruit $(\mathrm{cm})$, peel thickness $(\mathrm{cm})$, length and width of stone $(\mathrm{cm})$, percentage weight of peel, pulp and stone and ratio indices of length-width, peel-pulp and pulp-stone. The procedure given by Smith (1936) and outlined by Singh and Choudhary (1985) was used for calculation of discriminate function coefficients for various characters. The mean values of each character of individual genotype were multiplied by respective discriminate coefficients and the sum was taken as selection index for genotype. Finally, the genotypes were arranged in order of their merit to select the best variety for further improvement through breeding techniques. 
Table 1 Varietal indices for fruit yield/tree based on physical characters of fruits in mango

\begin{tabular}{|c|c|c|c|c|c|}
\hline \multirow[t]{2}{*}{ S.No. } & \multirow[t]{2}{*}{ Genotypes } & \multicolumn{2}{|c|}{ Selection indices for fruit yield/ tree } & \multicolumn{2}{|c|}{ Per se } \\
\hline & & On year & Off year & On year & Off year \\
\hline 1 & Alphonso & $1015.84 \mathrm{I}$ & 11.59 & $60.57 \mathrm{~V}$ & 27.57 \\
\hline 2 & Amrapali & 1218.37 & 26.35 & $45.54 \mathrm{I}$ & 33.73 \\
\hline 3 & B Green & 1078.66 & 17.35 & 80.54 & 19.57 \\
\hline 4 & Chousa & 1257.37 & 24.16 & 112.07 & 27.87 \\
\hline 5 & Dahiyar & 1324.06 & 8.07 & 114.97 & 19.27 \\
\hline 6 & Dashehari & 1174.45 & -0.68 II & 72.08 & 14.80 IV \\
\hline 7 & Fazli & 1201.52 & 25.68 & 72.00 & $13.00 \mathrm{III}$ \\
\hline 8 & Gajaria & 1106.66 & 10.43 & 70.26 & $15.23 \mathrm{~V}$ \\
\hline 9 & Gulabkhas & 1078.94 & 13.62 & 63.24 & $10.70 \mathrm{I}$ \\
\hline 10 & Langra & 1054.94 IV & 14.42 & 87.24 & 16.67 \\
\hline 11 & Mallika & 1141.21 & 38.75 & $51.43 \mathrm{II}$ & 38.03 \\
\hline 12 & Neelum & 1319.27 & 17.50 & $60.41 \mathrm{IV}$ & 35.00 \\
\hline 13 & Safeda & 1396.58 & 0.52 III & 67.30 & 17.83 \\
\hline 14 & Sinduria & 1419.00 & $-5.01 \mathrm{I}$ & 59.89 III & $11.17 \mathrm{II}$ \\
\hline 15 & Totapari & 1251.47 & $49.50 \mathrm{III}$ & 111.44 & 57.80 \\
\hline 16 & Sehroli & 1284.43 & 19.64 & 84.07 & 25.43 \\
\hline 17 & Suvaranrekha & 1279.03 & 28.05 & 61.48 & 31.40 \\
\hline 18 & SBM 01-1 & 1172.09 & 40.91 & 184.95 & 42.17 \\
\hline 19 & SBM 01-2 & 1208.28 & 17.53 & 91.55 & 20.00 \\
\hline 20 & SBM 01-3 & 1514.04 & $7.58 \mathrm{~V}$ & 94.01 & 21.93 \\
\hline 21 & SBM 01-4 & 1517.83 & 13.27 & 92.30 & 20.70 \\
\hline 22 & SBM 01-5 & $1026.94 \mathrm{II}$ & 11.71 & 102.48 & 23.10 \\
\hline 23 & SBM 01-6 & $2349.19 \mathrm{~V}$ & 32.91 & 266.80 & 48.80 \\
\hline 24 & SBM 01-9 & 2421.64 III & 38.82 & $332.43 \mathrm{III}$ & $55.20 \mathrm{IV}$ \\
\hline 25 & SBM 01-10 & 2668.86 I & 34.91 & 307.64 IV & 50.93 \\
\hline 26 & SBM 01-11 & 2146.73 & 20.90 & 226.08 & 22.67 \\
\hline 27 & SBM 01-12 & 1939.36 & 58.85 II & 168.95 & $97.07 \mathrm{I}$ \\
\hline 28 & SBM 01-13 & $1035.06 \mathrm{III}$ & 26.83 & 90.26 & 41.80 \\
\hline 29 & SBM 01-14 & $1059.32 \mathrm{~V}$ & 29.18 & 92.64 & 46.87 \\
\hline 30 & SBM 01-15 & 1902.71 & 24.66 & 118.00 & 24.03 \\
\hline 31 & SBM 01-17 & 1478.81 & $46.77 \mathrm{IV}$ & 110.51 & 52.73 \\
\hline 32 & SBM 01-19 & 1905.24 & 33.36 & 96.37 & 28.77 \\
\hline 33 & SBM 01-20 & 1603.17 & 35.38 & 185.76 & 46.87 \\
\hline 34 & SBM 01-22 & 1657.42 & 34.36 & 160.66 & 40.03 \\
\hline 35 & SBM 01-23 & 1614.64 & 37.19 & 215.42 & 37.17 \\
\hline 36 & SBM 01-24 & 1614.45 & 32.61 & 195.30 & 44.23 \\
\hline 37 & SBM 01-25 & 1178.83 & 22.15 & 158.18 & 36.63 \\
\hline 38 & SBM 01-26 & 1408.59 & 41.97 & $362.63 \mathrm{II}$ & 68.07 III \\
\hline 39 & SBM 01-27 & 1451.48 & 21.11 & 123.39 & 29.50 \\
\hline 40 & SBM 01-28 & 1273.50 & 40.39 & 191.77 & $54.53 \mathrm{~V}$ \\
\hline 41 & SBM 01-29 & 1525.14 & $45.05 \mathrm{~V}$ & 201.32 & 48.60 \\
\hline 42 & SBM 01-30 & 2397.54 IV & 44.02 & $263.96 \mathrm{~V}$ & 51.07 \\
\hline 43 & SBM 01-33 & 1653.99 & 43.35 & 110.68 & 44.40 \\
\hline 44 & SBM 01-35 & 1253.67 & $62.04 \mathrm{I}$ & 388.92 I & 96.43 II \\
\hline 45 & SBM 01-36 & 2442.57 II & 42.89 & 225.88 & 40.07 \\
\hline 46 & SBM 01-37 & 2011.83 & 15.37 & 142.88 & 22.47 \\
\hline 47 & SBM 01-38 & 2311.94 & 29.82 & 212.35 & 37.90 \\
\hline 48 & SBM 01-39 & 1802.80 & $6.98 \mathrm{IV}$ & 90.51 & 17.23 \\
\hline
\end{tabular}

\section{Results and Discussion}

Significant differences among the genotypes were recorded for fruit yield/tree and all the physical characters of fruits including ratio indices. It indicates the existence of considerable variability for all the studied characters thus, offers good scope for the selection of desirable genotypes. The mean squares due to years was also significant for fruit yield/tree, peel thickness, percentage weight of peel and pulp, pulp to peel ratio and pulp to stone ratio. It revealed that these traits were influenced by the ambient climatic conditions prevailed in two years. The genotype and environment interaction was also significant for some of the fruit quality traits. Shrivastava et al. (1987), Kashyap and Jyotishi (1969), Samad and Faruque (1976), Kapse et al. (1989). Yadav et al. (1995), Singh (2002) and Dwivedi and Mitra (2003) have also reported significant variability for physical fruit appearance in fruit crops confirming the present findings.

The varietal indices for fruit yield/ tree based on linear combination of physical fruit characters was in between 1015.84 to 2668.86 and -0.01 to 62.04 during on and off years, respectively (Table 1). SBM 01-10 followed by SBM 01-36, SBM 01-9, SBM 01-30 and SBM 01-6 exhibited maximum estimates of selection indices during the on year. Alphonso followed by SBM 01-5, SBM 01- 
13, Langra and SBM 01-14 showed minimum estimates of selection indices in this year. During off year, SBM 01 36 recorded the maximum estimates of selection indices, followed by SBM 01-12, Totapari, SBM 01-17 and SBM 01-29 while, Sinduria followed by Dashehari, Safeda, SBM 01-39 and SBM 01-3 showed the minimum estimates for fruit yield/tree. The ranking pattern of the genotypes based on selection indices was different in two years, which may be due to genetic capability of alternate bearing in mango. Genotypes SBM 01-9, SBM 01-10, SBM 01-30, SBM 01-6 and SBM 01-36 showed maximum varietal indices and phenotypic performance in both the years thus, appeared promising for use in breeding programme aimed at genetic improvement in fruit yield/ tree in mango.

The present study thus conclude that landraces SBM 01-9, SBM 01-10, SBM 01-6 and SBM 01-13 appeared as higher yielder based on yield per se and genetic merits of fruit characters hence, these genotypes can be used in breeding programmes for genetic amelioration in fruit yield/ tree in mango. However, the study also suggests the testing of large number genotypes over years and environment for selection of genetically diverse genotypes in mango. It further suggests that promising landraces of Bhopal division of Madhya Pradesh be maintained in a natural park or mango garden to conserve the biodiversity in order to check the genetic erosion in mango.

\section{References}

Dwivedi AK, Mitra SK. 2003. Metroglyph analysis of fruit quality traits in litchi (Litchi chinensis Sonn.). Indian J. Hort. 60: 318-321

Fisher RA. 1936. The use of multiple measurements in taxonomic problems. Ann.Eugen. 7: 179-188

Kapse BM, Rane DA, Khedkar DM. 1989. Correlation between bio-chemical parameters and organoleptic evaluation in mango varieties. Acta Horticulturae 231: 756-762

Kashyap R, Jyotishi RP. 1969. Preliminary study of some quality mangoes in Madhya Pradesh. Indian J. Agron. 2: 1922

Samad MA, Faruque AHM. 1976. A study on the physical characteristics of some common mango varieties of Bangladesh. Bangladesh Hort. 4: 18-23

Shrivastava SS, Asati KP, Patel MP, Tiwari BL, Bhadauria UPS. 1987. Evaluation of mango varieties in Madhaya Pradesh. Indian J. Hort. 44: 197-201

Singh RK, Choudhary BD. 1985. Biometrical Methods in Quantitative Genetic Analysis. Kalyani Publ., New Delhi, India

Singh DB. 2002. Improvement of mango (Mangifera indica L.) for regular and early fruiting in Andaman. Indian J. Agri. Sci. 72: 631-634

Smith HF. 1936. A discriminant function for plant selection. Ann. Eugen. 7: 240-250

Yadav KS, Singh M, Yadava HS. 1995. Genetic variability and correlated response for physico-chemical traits in mango. Crop Res. 9: 277-282. 